\title{
AN ETHICS OF REPRESENTATION FOR INTERNATIONAL MARKETING
}

\author{
Janet L. Borgerson \\ Jonathan E. Schroeder
}

University of Exeter

Discussion Papers in Management

Paper number 04/03

ISSN 1472-2939

\begin{abstract}
This paper offers an ethical analysis of visual representation that provides criteria for and sheds light on the appropriateness dimension of marketing communications. It provides a theoretically informed framework for recognizing and understanding ethical issues in visual representation. An interdisciplinary conceptual review and analysis focuses on four representational conventions, synthesizing ethical concerns, to provide a broader context for recognizing and understanding ethical issues in marketing representation: face-ism, idealization, exoticization and exclusion. This framework is discussed and applied to marketing communications. It argues that valuations of communication appropriateness must be informed by an awareness of the ethical relationship between marketing representations and identity. It is no longer satisfactory to associate advertising solely with persuasion, rather advertising must be seen as a representational system, with pedagogical as well as strategic functions. We conclude by discussing the theoretical, research, and managerial implications that arise from an ethics of visual representation. Urges moving beyond an advertising = persuasion model to encompass representation and culture in marketing communication studies. Contributes to understanding the ethical implications of marketing communication. Challenges marketers and researchers to broaden their conception of marketing communication to one more consistent with an image economy.
\end{abstract}

Keywords: Advertising, Consumer Behaviour, Ethics, Image, International Marketing, Social responsibility, Visual Communication

Inter-disciplinary CSR Research Conference

'Ethical Issues and International Marketing' track

Nottingham, October 2004

Janet Borgerson, School of Business and Economics, University of Exeter, Streatham Court, Rennes Drive, Exeter, UK, EX4 4PU. Phone: +44 (0) 1392264502 Email: J.L.Borgerson@exeter.ac.uk

Jonathan Schroeder, School of Business and Economics, University of Exeter, Streatham Court, Rennes Drive, Exeter, UK, EX4 4PU. Phone: +44 (0) 1392262537 Email: J.E.Schroeder@exeter.ac.uk 
In contemporary marketing communications, images claim center stage. The focus on image - over and above function - challenges basic notions of marketing practice, shifts appropriate topics of analysis, and reinforces the visual domain's centrality. Serving as stimuli, signs, or representations that drive cognition, interpretation, and preference, images influence what we know and believe (cf. Zaltman, 2002). Not surprisingly, images constitute much corporate communication about products and services, economic performance, and organizational identity. Pictures of people - models, celebrity endorsers, spokespersons, "average" consumers, managers and employees - make up a large part of marketing imagery. Moreover, images provide resources for, and, hence, shape, our understandings of the world, including the identities of its people and places. If marketing communications depend upon images, including brand images, corporate images, product images, and images of identity, then ethical tools meant to provide guidance for international marketing communications must be capable of addressing the concerns that such depictions evoke.

In this paper, we investigate marketing communication's role in "the taken-forgranted political and ethical practices of envisioning others" (Heywood \& Sandywell, 1999, p. $\mathrm{x}$ ). Discussions of marketing ethics rarely include visual issues, apart from largely atheoretical concerns over shock advertising, sexual appeals, or stereotyping; rather, they typically revolve around deception, the questionable accuracy of product claims, and the targeting of vulnerable consumers, such as children (e.g., Smith \& Quelch, 1993). These approaches to marketing ethics generally adopt an information-based model of marketing communication, emphasizing marketing's role as a strategic conduit of information for consumers, rather than fully acknowledging how marketing also acts as a representational system that produces meaning outside the realm of the promoted product or service (see Schroeder \& Salzer-Mörling, 2005; Scott \& Batra, 2003). This situation emerges in part because of a failure to confront the ethical concerns that arise in the wake of the prominence of the image - including advertising images, corporate images, and images of identity within today's image economy.

Ethically motivated criticisms of marketing communications are often simplistically understood as generalized critiques of capitalism and related excessive consumption (e.g., Crane \& Matten, 2004; Thompson, 2004). Our work in marketing communication ethics does not include criticism of consumption per se, nor do we take a moralistic stance against materialism, or marketing's possible role in promoting materialistic desires. Rather, we have 
chosen to elaborate on ethical issues pertaining to representations of identity, in that represented identities profess to express something true or essential about those represented. Just as personnel policies have had to accommodate changing norms about hiring and promotion when it comes to women and minorities, marketing managers must be aware of representational practices that may cause harm. Our analysis concerns not only the ethical implications, or consequences, of representational conventions - customary ways of depicting products, people and identities - within marketing communications, but emphasizes the ethical context from which such representational conventions emerge.

Whereas discussions of marketing communication ethics often focus on appropriate use of images, most lack a conceptual framework for recognizing and understanding ethical issues in visual representation. Typical guidelines for marketing communication ethics list such items as legal matters, including false claims, misleading statements, and improper labeling, deceptive pricing, and image appropriateness, as relevant for ethical review (Armstrong, 2004; Crane \& Matten, 2004). However, ethical checklists provide few criteria by which to judge whether ads contain, for example, "sexual innuendos which are considered inappropriate for audience," or "no ethnic stereotyping." We introduce an ethics of visual representation that provides such criteria and shed light on the appropriateness dimension of marketing communications. Evaluations of ad appropriateness must be informed by an awareness of the ethical relationship between marketing representations and identity. We conclude by discussing the implications arising from an ethics of visual representation as a vital issue for international marketing communication practice and research.

\section{Visual Representation Within the Image Economy}

Visual images exist within a distinctive socio-legal environment - unlike textual or verbal statements, such as product claims or political promises, pictures cannot be held to be true or false. Images elude empirical verification. Thus, images are especially amenable in enabling strategists to avoid being held accountable for false or misleading claims. For example, cigarette manufacturers have learned not to make text-based claims about their products, relying instead on visual imagery such as the lone cowboy roaming the American west.

Concerns about the persuasive power and rhetorical influence of marketing images have been countered by references to so-called "postmodern" notions of resistance and rising advertising literacy (cf. Elliott \& Wattanasuwan, 1998; O’Donohoe \& Tynan, 1998; Pettigrew, 2001). That is, continued concern around marketing communication's power to 
exert influence and reinforce ethically irresponsible representations of identity, such as a beer company's sexist and long-running, imaginary "Swedish bikini team," has been met with claims that consumers knowingly interpret visual or text-based advertising messages, selectively choose meanings, and resist rhetorical persuasion. For example, a recent business ethics textbook downplays concerns about advertising's perpetuation of harmful stereotypes by claiming that many "social commentators [...] contend that, as a society, we have never been so informed and educated about the role of advertising, promotion, and branding as we are today" (Crane \& Matten, 2004, p. 276). On the contrary, we argue that, outside of university courses in communication, there is relatively little education about marketing communication's social, cultural, and pedagogical roles, nor about the production, history, and theory of visual representation.

Marketing communication's ubiquity does not necessarily improve one's capacity to see - to actively engage one's senses in reflective analysis (Schroeder, 2002). Further, it is unclear how each new generation of consumers might benefit from such so-called advertising literacy; that is, children are not born with the innate ability to understand the underlying context of cultural meanings at work in marketing communications, no matter how many times parents tell them that an advertised toy will only be fun for a few minutes, although it looks great in the ads, or that a pair of athletic shoes cannot really make you run faster, or that models really do not look like that in real life.

Even when consumers realize an image or image-based scenario is not "real," these images influence how they perceive and respond to their world. Whereas decades of women realize that the bloody shower scene in Alfred Hitchcock's harrowing film, Psycho, is not "real," images from that scene, and others like it, no doubt have discouraged many from enjoying a shower. Similarly, images of the "exotic other" - from Augustus Earle's sketches of early 1800s Pacific islanders and Edward S. Curtis's twentieth century photographs of Native Americans to the iconic native island girl in tropical holiday promotions, suntan lotion ads, and fashion shoots - give us a sense that we know places, times, and peoples that we have never experienced. Given such wide-ranging influence, recent work in marketing scholarship urges us to consider marketing images as cultural texts, and not merely as accurate or true strategic pictures that transparently record faces, families, or familiar products, services, and sights (Mick, Burroughs, Hetzel, \& Brannen, 2004, for a review; Schroeder, 2002; Scott, 1994).

Images in marketing communication frequently stand in for experience, especially when other sources have less prominence, and serve as a foundation for future attempts to 
comprehend and construct the world around us. As a result, images in marketing communications understandably have attracted attention from marketing strategists, advertising practitioners, and consumer researchers, and have increasingly evoked criticism from cultural theorists and policy makers. Moreover, although researchers increasingly acknowledge consumer response as fundamental to ad interpretation, the power of images is not well understood. Ours is not a naive claim that consumers believe artificial, stereotypical, or idealized realms do or can exist, or that consumers consume advertising images from a single, unitary, or predetermined (so-called "structuralist") perspective. Rather, marketing images contribute to the "reality" into which contemporary consumers are socialized and often evade notions of creative interpretation and critical resistance.

According to some critics, pictures themselves contain such potent rhetorical authority that they require drastic action to curb their persuasive appeal (see Latour \& Wiebel, 2002; McQuarrie \& Mick, 1999; Schroeder, 2002; Scott, 1994). For example, Dan Romer, from the Annenberg Public Policy Center, has argued that "banning pictures from ads would help end the image that smoking is fun and give marketing campaigns about tobacco dangers a chance to work" (“Cigarette Ads,” 2001, p. 6). Images of beautiful people exhibiting no signs of nicotine addiction or its debilitating effects help maintain a positive vision of smoking. This persuasive power of marketing images depends largely upon the rhetorical representational conventions of photographic reproduction; that is, advertising, corporate reports, packaging, product catalogs, promotional materials, and Web graphics rely heavily upon photographic information technology to produce meaning within a circuit of production and consumption.

Photographic images - including digital pictures, film, video, and Internet graphics perform so often and so fluidly for marketing, scientific, legal, and political purposes that it can be difficult to keep in mind that photographs are selectively edited and culturallyproduced images that exist within shifting planes of meaning and significance. Photographs often appear as if they are merely visual records of what has happened, how people look, or where events took place at a particular moment. Marketing communication researchers must acknowledge the subjectivity of visual representation in studying the commercial landscape that everyday consumers encounter, keeping in mind that art directors, photographers, advertising executives, and corporate strategists choose from a range of images and juxtapose these with product and text in order to create "ordinary advertisements."

Viewers make sense of visual images in a number of ways, many of which are automatic or without awareness (cf. Bargh, 2002). Many perceptual processes fluctuate 
between conscious and unconscious control. For example, cognitive as well as physiological processes govern eye movement, attention, and awareness. Perceptual codes influence visual information processing - Westerners generally read from left to right, and from top to bottom. Further, perceptual cues, such as relative size, shape, color, and symmetry contribute to consumer cognition at a level at which most are perhaps only dimly aware (cf. Arnheim, 1974). Objects or people that appear larger in the visual frame are generally ascribed more perceptual and symbolic importance than those that appear small. Representational conventions - or common patterns of portraying objects, people, or identities - work in conjunction with these perceptual and cultural processes that often elude marketing communication research.

\section{Ethical Foundations}

An image economy requires approaches to ethics and marketing communication that move beyond codes of conduct, individual manager's actions, or particular campaigns. Our ethics of visual representation focuses on representational practices and their ethical implications, as well as emphasizing the ethical context from which representational conventions emerge. Along these lines, philosopher Margaret Urban Walker (1998, p. 178) contended that the assumption that people are a kind or type is propagated and created by representational conventions, which "are among those that construct socially salient identities for people." She further argued that if representational practices "affect some people's morally significant perceptions of and interactions with other people, and if they can contribute to those perceptions or interactions going seriously wrong, these activities have bearing on fundamental ethical questions" (Walker, 1998, p. 179). One of the most serious outcomes of representational practices is that people's perceptions, even "misinformed perceptions", often have "the weight of established facts" (Gordon, 1995, p. 203).

Contemporary ethical theorists have written extensively on the relation between representation and identity, or, ontological status (e.g., Bartky, 1990; Borgerson, 2001; Butler, 1987/1999; Gordon, 1995; Walker, 1998). Ontology centers on notions of being or identity - including human identity - who one is and who is not, including how relationships form and function. Ethics and ontology are linked by a concern about how visual markers such as skin color, embodiment, and gendered attributes represent or determine the status of human beings, particularly in the context of racism and sexism. Thus, what we think we know about others from representations of identity - including those within marketing 
communications - can affect how we see, treat, and understand them. Although alternative or resistant ways of looking at marketing images are possible, for example, reading mainstream ads as "gay" or interpreting sexist ads as "camp," "ironic," or "parody," this often simply reflects responses to or reconfigurations of the dominant system (Bourdieu \& Passeron, 1990; Kates, 1999). Representations of subordinate groups, for example, the poor (Kay \& Jost, 2003); the elderly (Carrigan \& Szmigin, 2000); and ethnic minorities (O’Barr, 1994; Taylor, Lee, \& Stern, 1995) rarely contradict and typically reproduce versions of subordination. For example, a comprehensive study of gender roles in television advertisements around the world, found that, despite some recent changes, ads "typically show men as authoritative and knowledgeable, whereas women are confined at home" (Furnham 1999, p. 434). In this way, the global commercial environment reproduces stereotypes that tend to limit women's opportunities and potential.

Basic communicative building blocks revolve around identity and difference (cf. Woodward, 1997). Ontological assumptions related to representations of identity, or assumptions about who and what the represented ones are, intersect with culturally defined hierarchies and dominant semiotics used in marketing communications. Dominant semiotics - grounding what categories, characteristics, or individual signs can mean within the dominant culture - prescribe and structure the elements of identity and difference that will be readily rendered as culturally intelligible. Semiotic meaning draws upon dualistic notions of being, identity and difference - such as self/other, male/female, white/black, rational/emotional, culture/nature, and normal/exotic - the opposed elements of which stabilize various positive and negative cultural associations and values. These semiotic associations are taken seriously, and often purport to express something natural and true. Setting one element against the other, for example white vs. black, has perpetuated and reinforced the dualistic hierarchical orderings that historically have favored the male, the white, and the rational (cf. Goldberg, 1993). Representational conventions in marketing communications draw upon these meaning systems, which may reinforce and reproduce damaging images of identity. In such a context, those associated with the privileged elements - the male, the rational, and the normal - stand in the position to claim knowledge of and denigrate all that is important to know about those associated with the subordinated elements - the female, the emotional, and the exotic (Borgerson, 2001).

This type of semiotically dualistic relation engages with the potential for epistemic closure, an ethical concept calling attention to the danger of typified representations of identity that increase the probability of human subjects interpreting what they experience or 
have represented to them as (stereo) typical. Typified representations, especially those that are racist or sexist, for example, may undermine a group's dignity and historical integrity and cast a demeaning light upon their physical and intellectual habits and ontological status as human beings (cf. Miller, 1994). A worldview informed by epistemic closure abstracts and condenses characteristics that create a familiar identity or pattern for beings of a kind. Epistemic closure leads an individual to believe that he or she knows the other's being completely, and this assumption denies the other status as human being and limits possibilities for human relationships (Gordon 1997). We contend that marketing images are never appropriate if they create epistemic closure without reasonable justification.

Marketing representations have the power to make us believe that we know something we have no experience of and to influence the experiences we have in the future. One often feels that one has learned something in observing or examining an image of a person or a geographic location, yet the way that such representations stand in when experience is lacking, or function in conjunction with experience, is of particular concern in marketing strategy and ethical analyses of marketing communications. How does one recognize ethically problematic representations? We argue that marketing requires a semiotic understanding of the cultural context in which images and representation circulate, which we sketch in the following sections.

\section{The Status of Marketing Communications}

Although marketing communication remains first and foremost a strategic tool, our analysis attempts to locate marketing images within a complex visual signifying arena that includes the interrelated domains of the aesthetic and the ethical (cf. Hall, 1997). Therefore, we situate marketing communications within a system of visual representation that creates meaning within the circuit of culture - often beyond the managerial control of any one organization or strategic vision. This circuit assumes that marketing messages both create and contribute to culture, largely via representational conventions (see Hall, 1997; Schroeder \& Zwick, 2004; Stern \& Schroeder, 1994; Thompson, 1995). A simple representational convention occurs in wristwatch ads, where most watches show the time as ten minutes past ten o'clock. Another familiar convention appears in the vertical orientation of celebrity "head shots", executive portraits, and pictures of satisfied consumers in "portrait" format that profoundly influenced media outlets such as magazines and newspapers. Other, more 
complicated conventions include the way fashion models pose in highly stylized manners, taught by modeling agencies and expected by photographers and designers.

Conventional views of representation hold that categories, such as objects, products, or consumers, exist in the material and natural world, and that their material characteristics define them in perfectly clear terms; representation, according to this view, is of secondary importance in the construction of meaning. In our view, meaning is produced or constructed by social and cultural forces; thus, representation assumes primary importance. Marketing scholarship has turned to the concept of representation for insight into diverse market-related phenomena, including advertising imagery, research methods, information technology, and photography (Stern, 1998). The process of representing objects, ideas and identities shapes how we think of them; in this way, representation enters into the very constitution of things and categories. Because representation refers to meaning production through language systems, how language - including visual representation - is used is central to creating meaning. Using representation as an analytic tool, researchers have emphasized how cultural practices, such as laws, rituals, norms, art, and advertising, contribute to meaning production within marketing (e.g., Andersson, Hedelin, Nilsson, \& Welander, 2004; Floch, 2001; Hall, 1997; Messaris, 1997; Schroeder, 2002; Schroeder \& Salzer-Mörling, 2005).

As part of a long line of visual expression, marketing representations remain embodied and embedded within a myriad of historical, cultural, and social situations, contexts, and discourses. At times this image creation draws upon and reinforces simplified, even subordinating, representations of cultural difference, group identity, and geographic specificity. According to cultural theorists Hall and Sealy (2001, p. 4), within visual representations: "profound differences of history, culture and experience have often been reduced to a handful of stereotypical features, which are "read" as if they represent a truth of nature, somehow indelibly described on the body. They are assumed to be "real" because they can be seen - difference, visible to the naked eye." Such epistemically closed representations of identity, harnessed in the attempt to create brand images or corporate identity, potentially undermine the full human status of represented groups and individuals (e.g., Dávila, 2001; Goffman, 1979; O’Barr, 1994; Schroeder and Borgerson, 1998; Stern, 1993; Williamson, 1978).

Identities that are exoticized, sexist, or racist, damage the reputation of represented groups, and associated group members, and manipulate their being for consumption by others. Furthermore, some identities are systematically excluded from marketing images, while others are represented in ethically problematic ways. The claim is not that some 
advertising, as well as other forms of marketing communications, might offend the concerned group and its members, but that certain forms of representation may limit their opportunities for the future by undermining or sabotaging their reputation. For example, Native American groups have protested professional sports teams such as the Atlanta Braves, the Cleveland Indians and the Washington Redskins' use of stereotyped, red-faced Indian figures in their promotional imagery, claiming that these representations have little to do with their identity, the oppressive history that they have endured, and their ongoing struggles to become valued American citizens (cf. Whitt, 1995).

\section{Representational Conventions}

Visual theorists have raised important points regarding the production of media representations and the potential repercussions for individuals, groups, and societies (e.g., Gross, 1988; Lutz \& Collins, 1993; van Leeuwen, 2000). Many studies have documented and criticized how ads often portray women and racial minorities in stereotyped and often negative ways (e.g., Bristol, Lee, \& Hunt, 1995; Cortese, 1999; Giroux, 1994; Goldman \& Papson, 1996; Schroeder, 2000; Stern, 1993; Whitt, 1995). In a groundbreaking discussion of "image ethics," media researcher Larry Gross began to articulate an ethics of representation pertaining to the media. He proposed two fundamental principles: first, groups should be allowed to speak for themselves. Second, media practices, including advertising, should be used to equalize the unequal distribution of power in society, or at least not to perpetuate inequality (Gross, 1988). These proposals have far reaching implications for making subordinated voices heard and for promoting human equality. Consistent with Gross's image ethics, we would hope that an ethics of representation could convince those in marketing communications, as Hippocrates suggested, to "first do no harm."

Visual communication theorist Theo van Leeuwen $(2000 ; 2001)$ identified two basic questions regarding the conventions of visual representation: (1) how are people depicted in relation to each other or their surroundings?, and (2) how are people depicted in relation to the viewer? He focuses on pictorial representations of people, and asks "what options, what choices does "the language of images" give us to depict people?" (van Leeuwen, 2000, p. 341). For van Leeuwen, representational choices revolve around issues of exclusion of certain identity groups, portrayed social roles, stereotypical depictions, and categorization into types. These representational variables often combine to produce epistemically closed 
portrayals; for example, creating a category of "third world poor" to juxtapose with images of affluence from the developed world.

Van Leeuwen identified several strategies (or representational conventions) of visual racism, in an in-depth study of how people are represented in images. Visual racism involves issues of "othering," exclusion, and stereotyping - where stereotyping involves not just negative cultural depictions but also showing certain people as homogeneous groups without distinguishing individual characteristics and differences. For example, typical National Geographic magazine photographs often portray "natives" as different from the assumed reader - other to the reader's self (Lutz \& Collins, 1993). Van Leeuwen's analysis of the relationship between the viewer and depictions of people, identified three pictorial dimensions: (1) the social distance - given certain assumptions about how the social status of one differs from the status of another, (2) the social relation - power differences, including how involved or detached the figures appear, and (3) the social interaction - the gaze of the depicted figure (outward, downward, and so forth) and its implications for interpersonal connection.

Visual representations express social psychological relations, such as closeness, involvement, and status (Larsen, Luna, \& Peraccchio, 2004; Nederveen Pieterse, 1992). Some images invite interaction; whether the pictured person looks at, or gazes at, the viewer is critical in determining the potential (implied) relationships. Although these interactions or relations are imagined, viewers often perceive depicted individuals or groups as though they were strangers or friends, and, in terms of the camera angle, physically or socially above or below them. Camera angles also structure social relations, whether the viewer sees depicted subjects from above, eye level, or below; and can allude to symbolic involvement or detachment, coming face to face with someone, confronting them, or sidling up to them (van Leeuwen, 2000). A woman lying down can be generally said to exhibit less status, as an object of the male gaze (Goffman, 1979; Schroeder \& Borgerson, 1998). In a television advertisement, a "long shot," (one taken from far away, often with a telephoto lens), may indicate a distant relationship between characters, or between a character and the viewer, whereas a close-up is likely to connote intimacy.

These pictorial dimensions - social distance, social relation, and social interaction indicate a larger ethics of power and representation articulated within the gaze. To gaze implies more than to look at - it signifies a psychological relationship of power, in which the gazer is superior to the object of the gaze. Royalty gaze upon their subjects, viewed as property in the kingdom. Explorers gaze upon newly "discovered" land as colonial resources. 
Although recent theoretical treatments of the gaze acknowledge the myriad forms it may take, including a female gaze, advertising has been called an extreme expression of the male gaze, producing stereotyped and typified representations of men and women, the good life, and sexual fantasy (cf. Jacobson \& Mazur, 1995; Schroeder \& Borgerson, 2003; Schroeder \& McDonagh, 2005; Stern, 1993).

Marketing communications often depend upon the gaze to build relationships between consumers and fashion models, products, or companies. Shields and Heinecken's (2002, p. 83 ) research suggested how the gaze interacts with marketing communications: "while both men and women discussed the pleasure of looking at attractive females, men tended to make their comments within the larger context of the way they look at women in general, not confining their comments to the advertisements in front of them." For example, one male respondent reported that ads please him as a "visual stimuli kind of thing. I find women attractive and it makes me feel good to look at them...I guess I equated that with having a lot of fun. You know, being at a party...kind of like being on a beer commercial" (in Shields \& Heinecken, 2002, p. 84). Here the male consumer's gaze expresses social distance, social relation, and social interaction; he apparently believes that he is in a position to judge and appreciate attractive women, that he is welcome to party with them. In this way, marketing communications help and compel him to define his identity and his potential relationship with women.

The representational choices described by van Leeuwen, in conjunction with such pictorial variables as distance, angle, and gaze, animate images of identity, and help point to marketing practices, such as drawing unreflectively upon semiotic meanings and representing people as "others" or persons not like "us," that can produce unethical imagery (Borgerson \& Schroeder, 2002; O’Barr, 1994; van Leeuwen, 2000). Further, these choices may lead to subtle racist, sexist, and or epistemically closed representations that could undermine marketing communication, particularly global campaigns aimed at diverse consumers. Whereas van Leeuwen proposed a rather deterministic model of pictorial meaning, we argue for an approach that considers the cultural and ethical context in which meaning arises, which we believe can supply the necessary theoretical underpinning for an ethics of visual representation.

In the next section, we present several representational conventions to ground analysis and enhance understanding of the ethical implications of images in marketing communication. We discuss how the language of images presents marketers with choices 
about how to depict people, among other subjects, and how these choices coalesce into certain representational conventions.

\section{A Framework for Image Analysis}

In order to articulate an ethics of representation for marketing communication, we focus here on four representational conventions to provide a broader context for recognizing and understanding ethical issues in marketing representation:

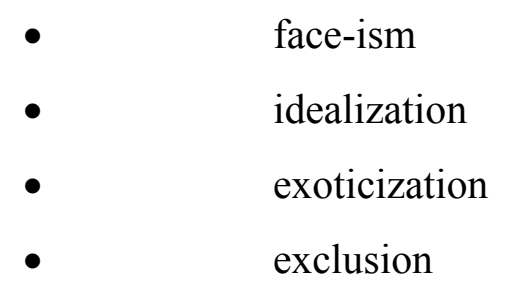

Face-ism describes how mass media systematically show men with more prominent faces than women and how women are negatively affected by this representational convention (figures 1 and 2). Idealization concerns how marketing communications routinely depict ideal types (figure 3)- young, thin models, unrealistic scenarios, or unattainable goals - and the negative effects these often have, beginning in childhood (e.g., Belk \& Pollay, 1987; Martin \& Gentry, 1997; Richins, 1991; Shields \& Heinecken, 2002). Exoticization, which refers to the process of making someone seem exotic, strange, or different in ways that call attention to certain identity characteristics, such as skin color, dress, or appearance can be seen as a crucial category (figures 4 and 5). Exclusion indicates how certain types of people for example, poor, marginalized, or under-represented individuals and groups - have traditionally been left out of the marketing communication pantheon.

These analytic categories, discussed in greater detail below, together with aforementioned pictorial dimensions, can be useful in generating ethical insights and investigating how marketing communications represent and construct identities. However, it must be kept in mind that they do not comprise an exhaustive list and may at times overlap. We believe that they illuminate the key representational tensions and ethical issues within contemporary marketing communications.

Face-ism

In their classic study on the forms and consequences of stereotyping, Archer and his colleagues identified a pervasive form of representational bias that they call face-ism. Five 
studies involving various media were conducted to investigate the facial prominence of men and women and subsequent social psychological consequences. Their interest in facial prominence stemmed from their belief that, "because the face and head are the centers of mental life - intellect, personality, identity, and character - the relative prominence of this part of the anatomy may be symbolically consequential" (Archer, Iritani, Kimes, \& Barrios, 1983, p. 726). The phenomenon of face-ism refers to the prominence or significance of the face in photographs or images, and can be indexed through a consideration of a ratio based on two linear measurements - the distance between the top of the subject's head and chin divided by the distance between the top of the head and the lowest visible part of the subject's body. Thus a "mug shot," which shows only the head of a recently arrested person, has more facial prominence than a full-body picture of a runway model. Because it is a ratio, the faceism index can be applied to any human image, including people depicted in advertisements and other marketing communications.

Archer and his colleagues found that males were portrayed with more prominent faces than females in news photographs appearing in American periodicals, in newspapers from various countries, and in art portraits dating from the past 600 years. When asked to draw human figures, both male and female research participants drew women with less prominent faces and more prominent bodies. In a crucial follow- up experiment, the researchers demonstrated the possible negative consequences of face-ism. In rating people portrayed in manipulated photographs, participants consistently rated those with less prominent faces as less intelligent, less ambitious, and less attractive, regardless of the sex of either the rater or the person in the photograph (Archer et al., 1983).

In other words, when either men or women appear in images that show more of their body, viewers tended to attribute fewer positive attributes to them. Those who were portrayed with greater relative facial prominence were perceived as more intelligent, ambitious, and physically attractive, suggesting "that perceived intellectual (and other) qualities may be significantly and favorably affected by something as simple as the relative prominence of the person's face [in a photograph]" (Archer et al., 1983, p. 732). Interestingly, these results suggest that both men and women could potentially suffer the effects of face-ism from being shown with less relative facial prominence, However, despite the progress of the feminist movement, increased attention to the women's market, and the growing number of women in roles of power, face-ism remains a well substantiated yet little known representational convention that continues to favor men (King, 2002; Levesque \& Lowe, 1999). 
Idealization

A growing body of consumer research has revealed specific links between glamorized images in television ads and dissatisfaction with the self (e.g., Peck \& Loken, 2004; Richins, 1991). Photographic techniques, such as digitization, cropping, and image manipulation can accelerate the extent to which marketing messages negatively affect self-image. In a recent analysis of the effects of idealized imagery in marketing communications, Shields and Heinecken (2002, p. xv) argued that:

There is profound evidence suggesting that girls and young women [in Western cultures]are particularly vulnerable to particular kinds of mass media messages: those pertaining to body images, size, and appearance. They are not more vulnerable than boys or men because they are somehow weaker against the power of these messages. They are more vulnerable because the culture they are born into subscribes to the notion that women should be the objects of vision. Female bodies are held up to inspection to a much greater degree than are men's in this culture. Women's worth is judged generally by appearance first and abilities second.

Idealized bodies, in particular, help construct notions about female identity, attractiveness, and normality in ways that can damage identity. Critically, images influence how we think about the ideal or good life, what is sexy, and what will be seen as attractive by desired others (cf. Belk \& Pollay, 1985; Crocker \& Linden, 1998; Pollay, 1985). These points were reflected in some of the comments of young women interviewed by Shields and Heinecken (2002, p. 86); for example: “. . . making women appear to be objects [...] hurts women's image to men" and "it hurts because this ad is trying to show that we are supposed to be there for men. We are men's obsession. We are just lying there, waiting for them." Such comments point to the negative role of marketing communication's identity constructions as they illuminate ethical problems with contemporary imagery.

\section{Exoticization}

A particularly virulent form of stereotyping that combines several problematic representational conventions, exoticization affects many identity categories appearing in marketing communications, including Africans, Asians, Blacks, Native Americans, and indigenous peoples (Desmond, 1999; O’Barr, 1994; Williamson, 1986; Woodward, 1997). For example, marketing representations of Hawaiians, Polynesians, and other Pacific 
Islanders, reflect a dominant cultural view of the exotic other (Costa, 1998). In other words, "Hawaiians are repeatedly presented as people whose lives are less complex and less valuable than the lives of Euroamericans" (Wood, 1999, p. 113). Research on marketing representations from advertising, tourist brochures, record albums, Hollywood films, and kitsch Hawiiana has revealed that exoticized (and often eroticized) depictions of "natives" are commonly used to portray the image of Hawaii (Borgerson \& Schroeder, 2002). This vision of an exotic vacation paradise currently informs tourism campaigns for the Virgin Islands, Ibiza, Jamaica and Bali, positioning islanders against tourists, in a kind of representational pattern that may undermine identities and reputations (cf. Borgerson \& Schroeder, 2003).

Visions of "exotic" peoples do not just exist "out there" but must be created and recreated. Much of the ideological power of the representations lies in their almost infinite repetition - similar images are presented over and over, in a wide variety of marketing contexts and epochs. Unfortunately absent from most marketing communications about Hawaii, island resorts, and paradisal escapes is the reminder that exoticization always functions within a context of unequal power and epistemic closure. The indigenous peoples of Hawaii have a rich, largely unrepresented culture, yet the image of Hawaii that dominates many people's imagination comes from marketing communications, travel brochures, cookbooks, record albums, musicals, and films. These representations are instrumental in constructing the image of Hawaii as an exotic, primitive paradise within colonial, patriarchal, and racist discourses, placing Polynesia within an "orientalist" discourse of the other (e.g., Said, 1978).

\section{Exclusion}

Exclusion indicates the likelihood of not representing particular people in marketing communications. In other words, it marks an absence. Although this seems unlikely in an era of increasingly focused target marketing, some people, such as minorities, the poor, or otherwise "different" individuals, have been traditionally underrepresented (or excluded entirely) from marketing images. For example, companies such as BMW, Timberland, Tommy Hilfiger, and Abercrombie \& Fitch have come under fire from minority groups for not reflecting them as consumers or for excluding them from the brand's identity, by not including diversity within advertising, catalog imagery, and websites (cf. Berger, 2001). By excluding - to varying degrees - certain representations, possible meanings, interpretations, and understandings are limited in ways that may negatively influence certain individuals, groups, scenarios, and even geographic locations. 
Some may argue that increasing representation of the formerly excluded in marketing images is an improvement over earlier periods, when many marginalized groups were not represented at all. One might think that simply including images of under-represented or marginalized cultural groups in marketing communications would reduce exclusion's ethical impact, but this strategy often leads to exoticized images, images informed by typicality and "token" images. For example, Benetton's approach to cultural "inclusion" has been widely criticized as perpetuating stereotypes of difference - an ironic result that illustrates the complex intersection of identity, representation, and marketing within the global economy.

\section{Consumer Interpretation and Representational Conventions}

Representational conventions such as these, and related pictorial dimensions, may operate within marketing communications to systematically and unconsciously influence consumer perception at a fundamental cognitive level, via a process that we have called tacit interpretation (Schroeder \& Borgerson, 2004). Relatively few people realize how face-ism, idealization, exoticization, and exclusion pervade marketing representations, or how they influence perceptual processes. We are not implying that consumers or marketers are unaware of representational conventions; nevertheless, consumers may remain unable to resist or deconstruct them (cf. Kates, 1999; Thompson \& Haytko, 1998). In many cases, the typified, idealized, exoticized, or excluded identity stands in for the human being within representational practices. Representational conventions such as face-ism are especially significant because they establish a link between visual representation and attributions, illuminating the central role visual representations and semiotic dualisms have in social stereotyping.

\section{Marketing Research Implications}

Representational conventions can be seen as part of a class of tacit interpretation effects that lead people to judge others on the basis of subtle visual cues, social categories, and cognitive schemas. Moreover, they generally serve to psychologically justify the status quo, operating as identifiable and stable interpretive conventions, which often operate unconsciously (cf. Bargh, 2002; Schroeder \& Borgerson, 2004). Additionally, representational conventions point to potential blind spots in consumers' responses to images of identity, alerting researchers to methodological implications. That is, conventions, such as face-ism, idealization, exoticization, and exclusion should be considered within research design, 
particularly experiments that manipulate pictures of people. Any study that employs depictions of people may be affected by these kind of representational conventions.

For example, in their research on how cropped photographs affect product evaluations, Peracchio and Myers-Levy (1994, p. 192) showed some participants an ad with an "exotic-looking women who appeared to be consuming the product." It is unclear, from their brief description, what was "exotic" about the woman, how this was visually represented, and how her appearance might have affected viewer's perceptions about her and the product she appeared to be consuming - or why the researchers used this particular image at all. Further, "exotic" is not a neutral descriptive term - it invokes a long history of Orientalism that undermines and undervalues the intellectual capacities and human qualities of those labeled "exotic" (e.g., Said, 1978). Thus, by depicting an "exotic-looking woman" in their study, they may have inadvertently confounded their experimental design, as research participants may have responded to the representational ramifications of exoticism. In this way, representational conventions have the potential to compromise research validity. Thus, each study that utilizes images of people needs to assess the potential for representational bias, including exoticization and face-ism.

\section{Conclusion}

Marketers must become culturally, ethically, and visually literate in representation and semiotics if they are to recognize and understand ethical problems in international marketing communications. Hence, judgments of image appropriateness should be informed by an awareness of potential epistemic closures. We insist that an ethics of representation must invoke issues that arise when brand identity, corporate communication, and visual strategy relies upon representations of identity. We argue that ethical analyses of marketing communications must offer accounts for how its images represent identity. Moreover, representational conventions point to potential blind spots in consumer's responses to images of identity, alerting marketers to gaps between strategic conceptions of brand identity and consumer perceptions about brand image.

Linking marketing communication to ontological dilemmas in identity representation enables researchers to recognize a global communication system based on visual images. Recognizing the theoretical, methodological, and strategic implications of face-ism, idealization, exoticization, and exclusion contribute to understanding the ethical implications of marketing communication. Further ethical issues point to marketing's commodification of 
human beings, employing bodies and body images to promote products and services, thus associating identity with consumption, and existence with market processes.

How can marketing prevent these problems in visual representation? We have suggested ways to clarify complex issues of representational ethics in marketing by applying contemporary work in communication theory, marketing, and philosophical ethics. When marketing campaigns represent identities of groups or individuals so that the representations themselves purport to express something true or essential about those represented, aesthetic and ethical questions intersect, and allow certain ontological assumptions to emerge. In addition to damaging the reputation of members of represented groups, some forms of representation that are exoticized, stereotypical, sexist, or racist actually manipulate these groups for consumption by others. Given extant power inequalities and lack of access to mass media forms of representation, subordinated or oppressed individuals and groups often do not have much control over how they are represented, particularly within the discourse of marketing communication. We do not suggest that marketing communication causes these cultural prejudices, rather that there are relatively stable problematic representational conventions that might be avoided through close ethical analysis of marketing campaigns. 
References

Andersson, S., Hedelin, A., Nilsson, A., \& Welander, C. (2004). Violent advertising in fashion marketing. Journal of Fashion Marketing \& Management, 8, 96-112.

Archer, D., Iritani, B, Kimes, D., \& Barrios, M. (1983). Face-ism: Five studies of sex differences in facial prominence. Journal of Personality and Social Psychology, 45, $725-735$.

Armstrong, J. S. (2004), Evaluating ads. Available: www.advertisingprinciples.com.

Arnheim, R. (1974). Art and visual perception. Berkeley: University of California Press.

Bargh, J. A. (2002). Losing consciousness: Automatic influences on consumer judgment, behavior, and motivation. Journal of Consumer Research, 29, 280-285.

Bartky, S. (1991). Femininity and domination. New York: Routledge.

Belk, R. W., \& and Pollay, R. W. (1985). Images of ourselves: The good life in twentieth century advertising. Journal of Consumer Research, 11, 887-97.

Berger, W. (2001). Advertising Today. London: Phaidon.

Borgerson, J. (2001). Feminist ethical ontology: Contesting "the bare givenness of intersubjectivity". Feminist Theory, 2, 173-187.

Borgerson, J. L., \& Schroeder, J. E. (2002). Ethical issues of global marketing: Avoiding bad faith in visual representation. European Journal of Marketing, 36, 570-594.

Borgerson, J. L., \& Schroeder, J. E. (2003). The lure of paradise: Marketing the retro-escape of Hawaii. In S. Brown and J.F. Sherry, Jr. (Eds.), Time, space and place: Retroscapes rising (pp. 219-237). New York: M.E. Sharpe.

Bourdieu, P., \& Passeron, J. C. (1990). Reproduction. London: Sage.

Bristor, J., Lee, R. G. \& Hunt, M. (1995). Race and ideology: African American images in television advertising. Journal of Public Policy \& Marketing, 14, 1-24.

Butler, J. (1999/1987). Subjects of desire: Hegelian reflections in twentieth-century France. New York: Columbia University Press.

Carrigan, M., \& Szmigin, I. (2000). Advertising and older consumers: Image and ageism. Business Ethics: A European Review, 9, 42-50

Cigarette ads still enticing teens to smoke, study shows. (2001, June 12). The Providence Journal-Bulletin, p. 6.

Cortese, A. J. (1999). Provocateur: Images of women and minorities in advertising. Lanham, MD: Rowman \& Littlefield.

Costa, J. A. (1998). Paradisal discourse: A critical analysis of marketing and consuming Hawaii. Consumption Markets \& Culture, 1, 303-346.

Crane, A., \& Matten, D. (2004). Business ethics: A European perspective. Oxford: Oxford University Press.

Crocker, D. A., \& Linden, T. (Eds.) (1998). Ethics of consumption: The good life, justice and global stewardship. Lanham, MD: Rowman \& Littlefield.

Dávila, A. (2001). Latinos, inc.: The marketing and making of a people. Berkeley: University of California Press.

Desmond, J. (2003). Consuming behavior. New York: Palgrave.

Desmond, J. C. (1999). Staging tourism: Bodies on display from Waikiki to Sea World. Chicago: University of Chicago Press.

Elliott, R., \& Wattanasuwan, K. (1998). Brands as symbolic resources for the construction of identity. International Journal of Advertising, 17, 131-144.

Floch, J.-M. (2001). Semiotics, marketing and communication: Beneath the signs, the strategies, trans. R. O. Bodkin. Hampshire: Palgrave. 
Furnham, A. (1999). Sex role stereotyping in television commercials: A review and comparison of fourteen studies done in five continents over 25 years. Sex Roles, 41 (September), 413-4317.

Giroux, H. A. (1994). Disturbing pleasures: Learning popular culture. New York: Routledge.

Goffman, E. (1979). Gender advertisements. New York: Harper \& Row.

Goldberg, D. T. (1993). Racist culture: Philosophy and the politics of meaning. Oxford: Blackwell.

Goldman, R., \& Papson, S. (1996). Sign wars: The cluttered landscape of advertising. New York: Guilford.

Gordon, L. R. (1995). Bad faith and antiblack racism. Atlantic Highlands, NJ: Humanities Press.

Gordon, L. R. (1997). Her Majesty's Other children: Sketches of racism from a neocolonial age. Lanham, MD: Rowman \& Littlefield.

Gross, L. (1988). The ethics of (mis) representation. In L. Gross, J.S. Katz \& J. Ruby (Eds.), Image ethics (pp. 188-202). New York: Oxford University Press.

Hall, S. (Ed.) (1997). Representation: Cultural representations and signifying practices. London: Open University Press/Sage.

Hall, S., \& Sealy, M. (2001). Different: Contemporary photographers and Black identity. London: Phaidon.

Heywood, I., \& Sandywell, B. (1999). Introduction: Explorations in the hermeneutics of the visual. In I. Heywood \& B. Sandywell (Eds.), Interpreting visual culture: Explorations in the hermeneutics of the visual (pp. ix-xviii). London: Routledge.

Jacobson, M. F., \& Mazur, L. A. (1995). Marketing madness: A survival guide to consumer society. Boulder, CO: Westview Press

Kates, S. M. (1999). Making the ad perfectly queer: Marketing "normality" to the gay men's community. Journal of Advertising, 28, 25-37.

Kay, A. C., \& Jost, J. T. (2003). Complementary justice: Effects of "poor but happy" and "poor but honest" stereotype exemplars on system justification and implicit activation of the justice motive. Journal of Personality and Social Psychology, 85 (5), 823-837.

King, J. M. (2002). Photographic images of gender and race in Fortune 500 company Web Sites in the United States. Business Research Yearbook 7, 852-856.

Larson, V., Luna, D., \& Peracchio, L. A. (2004). Points of view and pieces of time: A taxonomy of image attributes. Journal of Consumer Research, 31 (1), 102-111.

Latour, B., \& Weibel, P. (Eds.) (2002). Iconoclash: Beyond the image wars in science, religion, and art. Cambridge, MA: MIT Press.

Levesque, M. J., \& Lowe, C. A. (1999). Face-ism as a determinant of interpersonal perceptions: The influence of context on facial prominence effects. Sex Roles, 41 (3/4), 241-259.

Lutz, C. A., \& Collins, J. L. (1993). Reading National Geographic. Chicago: University of Chicago Press.

Martin, M. C., \& Gentry, J. W. (1997). Stuck in the model trap: The effects of beautiful models in ads on female pre-adolescents and adolescents. Journal of Advertising, 26, 19-33.

McQuarrie, E. F., \& Mick, D. G. (1999). Visual rhetoric in advertising: Text-interpretive, experimental, and reader-response analyses. Journal of Consumer Research, 26, $37-$ 54.

Messaris, P. (1997). Visual persuasion: The role of images in advertising. Newbury Park, CA: Sage. 
Mick, D. G., Burroughs, J. E., Hetzel, P., \& Brannen, M. Y. (2004). Pursuing the meaning of meaning in the commercial world: An international review of marketing and consumer research founded on semiotics. Semiotica, in press.

Miller, D. (1994). Ontology and style. In J. Friedman, J. (Ed.), Consumption and identity (pp. 71-96). Amsterdam: Harwood.

Natanson, M. (1986). Anonymity: A study in the philosophy of Alfred Schutz. Bloomington: Indiana University Press.

Nederveen Pieterse, J. (1992). White on Black: Images of Africa and Blacks in Western popular culture. New Haven: Yale University Press.

O'Barr, W. M., (1994). Culture and the ad: Exploring Otherness in the world of advertising. Boulder, CO: Westview.

O'Donohoe, S., \& Tynan, C. (1998). Beyond sophistication: Dimensions of advertising literacy. International Journal of Advertising, 17, 467-482.

Peck, J., \& Loken, B. (2004). When will larger-sized female models in advertisements be viewed positively? The moderating effects of instructional frame, gender, and need for cognition. Psychology \& Marketing, 21 (6), 425-442.

Peracchio, L., \& Myers-Levy, J. (1994). How ambiguous cropped objects in ad photos can affect product evaluations. Journal of Consumer Research, 21, 190-204.

Pettigrew, S. (2001). King or pawn? The role of the Australian beer drinker. Journal of Research for Consumers, 2. Available: www.jrconsumers.com.

Pollay, R. (1986). The distorted mirror: Reflections on the unintended consequences of advertising. Journal of Marketing, 50, 18-36.

Richins, M. L. (1991). Social comparison and the idealized images of advertising. Journal of Consumer Research, 18, 71-83.

Said, E. (1978). Orientalism. New York: Vantage Press.

Schroeder, J. E. (1998). Consuming representation: A visual approach to consumer research. In B. B. Stern (Ed.), Representing consumers: Voices, views and visions (pp. 193230). London: Routledge.

Schroeder, J. E. (2000). Édouard Manet, Calvin Klein and the strategic use of scandal. In S. Brown \& A. Patterson (Eds.), Imagining Marketing: Art, Aesthetics, and the AvantGarde (pp. 36-51). London: Routledge.

Schroeder, J. E. (2002). Visual consumption. London: Routledge.

Schroeder, J. E., \& Borgerson, J. L. (1998). Marketing images of gender: A visual analysis. Consumption Markets \& Culture, 2, 161-201.

Schroeder, J. E., \& Borgerson, J. L. (2003). Dark desires: Fetishism, ontology and representation in contemporary advertising. In T. Reichert \& J. Lambiase (Eds.), Sex in advertising: Perspectives on the Erotic Appeal (pp. 65-87). Mahwah, NJ: Lawrence Erlbaum Associates.

Schroeder, J. E., \& Borgerson, J. L. (2004). Tacit processes in consumer interpretation. In S. Brown \& D. Turley (Eds.), European Advances in Consumer Research (vol. 7, pp. 70-72). Valdosta, GA: Association for Consumer Research.

Schroeder, J. E., \& McDonagh, P. (2005). The logic of pornography in digital camera promotion. In J. Lambiase \& T. Reichert (Eds.), Sex in promotional culture: The erotic content of media and marketing. Mahwah, NJ: Lawrence Erlbaum Associates.

Schroeder, J. E., \& Salzer-Mörling, M. (2005). Brand culture. London: Routledge.

Schroeder, J. E., \& Zwick, D. (2004). Mirrors of masculinity: Representation and identity in advertising images. Consumption Markets \& Culture, 7, 21-52.

Scott, L. A. (1994). Images of advertising: The need for a theory of visual rhetoric. Journal of Consumer Research, 21, 252-273. 
Scott, L., \& Batra, R. (Eds.) (2003). Persuasive imagery: A consumer response perspective. Mahwah, NJ: Lawrence Erlbaum Associates.

Shields, V. R., \& Heinecken, D. (2002). Measuring up: How advertising affects self-image. Philadelphia: University of Pennsylvania Press.

Smith, N. C., \& Quelch, J.A. (1993). Ethics in marketing. Homewood, IL: Irwin.

Stern, B. B. (1993). Feminist literary criticism and the deconstruction of ads: a postmodern view of advertising and consumer research. Journal of Consumer Research, 19, 556566.

Stern, B. B. (1998). Introduction: the problematics of representation. In B. B. Stern, (Ed.), Representing consumers: Voices, views, and visions (pp. 1-23). New York: Routledge.

Stern, B. B., \& Schroeder, J. E. (1994). Interpretive methodology from art and literary criticism: a humanistic approach to advertising imagery. European Journal of Marketing, 28, 114-132.

Taylor, C. R., Lee, J. U., \& Stern, B. B. (1995). Portrayals of African, Hispanic, and Asian Americans in Magazine Advertising. American Behavioral Scientist, 38 (4), 608-621.

Thompson, C. J. (1995). A contextualist proposal for the conceptualization and study of marketing ethics. Journal of Public Policy \& Marketing, 14, 177-191.

Thompson, C. J. (2004). Dreams of Eden: A critical reader-response analysis of the mythoideologies encoded in natural health advertisements. In K. Ekström \& H. Brembeck (Eds.), Elusive consumption (pp. 175-204). Oxford: Berg.

Thompson, C. J., \& Haytko, D. L. (1997). Speaking of fashion: Consumers' uses of fashion discourses and the appropriation of countervailing cultural meanings. Journal of Consumer Research, 24, 15-42.

Walker, M. U. (1998). Moral understandings: Feminist studies in ethics. New York: Routledge.

van Leeuwen, T. (2000). Visual racism. In M. Reisigl \& R. Wodak (Eds.), The semiotics of racism: Approaches in critical discourse analysis (pp. 333-350). Vienna: Passagen Verlag.

van Leeuwen, T. (2001). Semiotics and iconography. In T. van Leeuwen \& C. Jewitt (Eds.), Handbook of visual analysis (pp. 92-118). London: Sage.

Whitt, L. A. (1995). Cultural imperialism and the marketing of Native American culture, American Indian Culture and Research Journal, 19, 1-31.

Williamson, J. (1978). Decoding advertisements. London: Marion Boyers.

Williamson, J. (1986). Women is an island: Femininity and colonization. In T. Modleski (Ed.), Studies in entertainment: Critical approaches to mass culture (pp. 99-118). Bloomington: Indiana University Press.

Wood, H. (1999). Displacing natives: The rhetorical production of Hawai'i. Lanham, MD: Rowman \& Littlefield.

Woodward, K. (Ed.) (1997). Identity and difference. London: Sage/Open University Press. Zaltman, G. (2002). How customers think. Boston: Harvard Business School Press. 

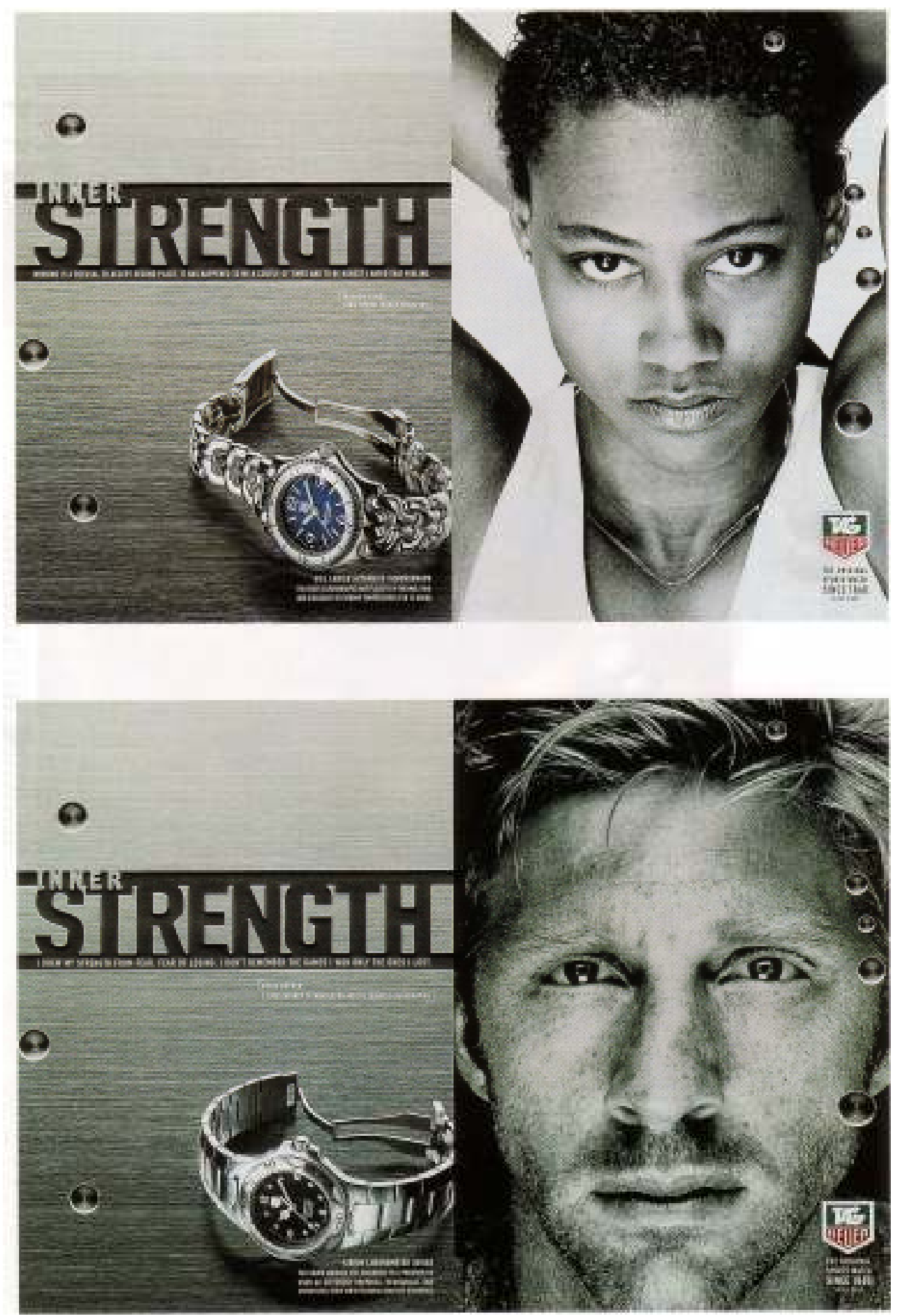

Figure 1 Face-ism example I 


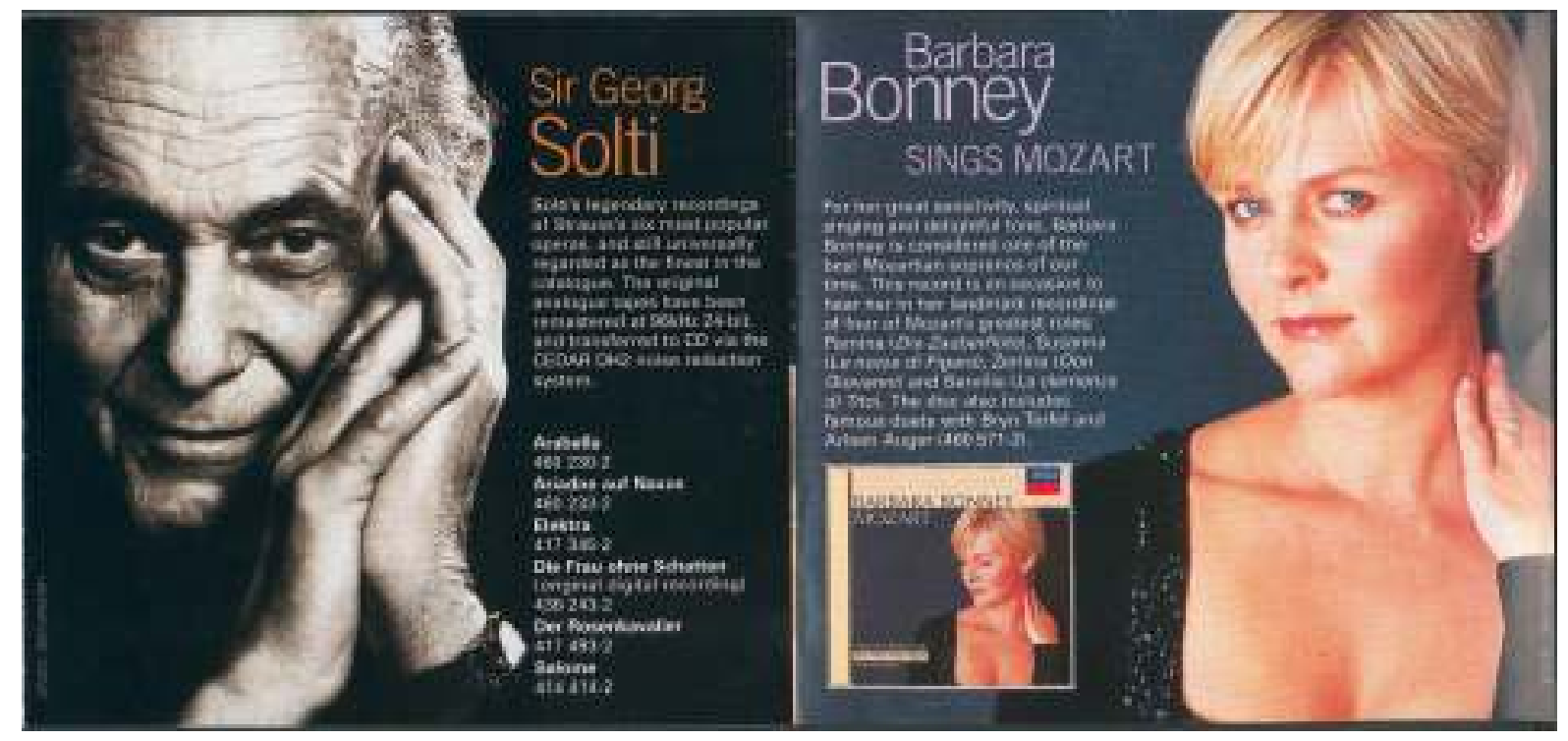

Figure 2 Face-ism example II

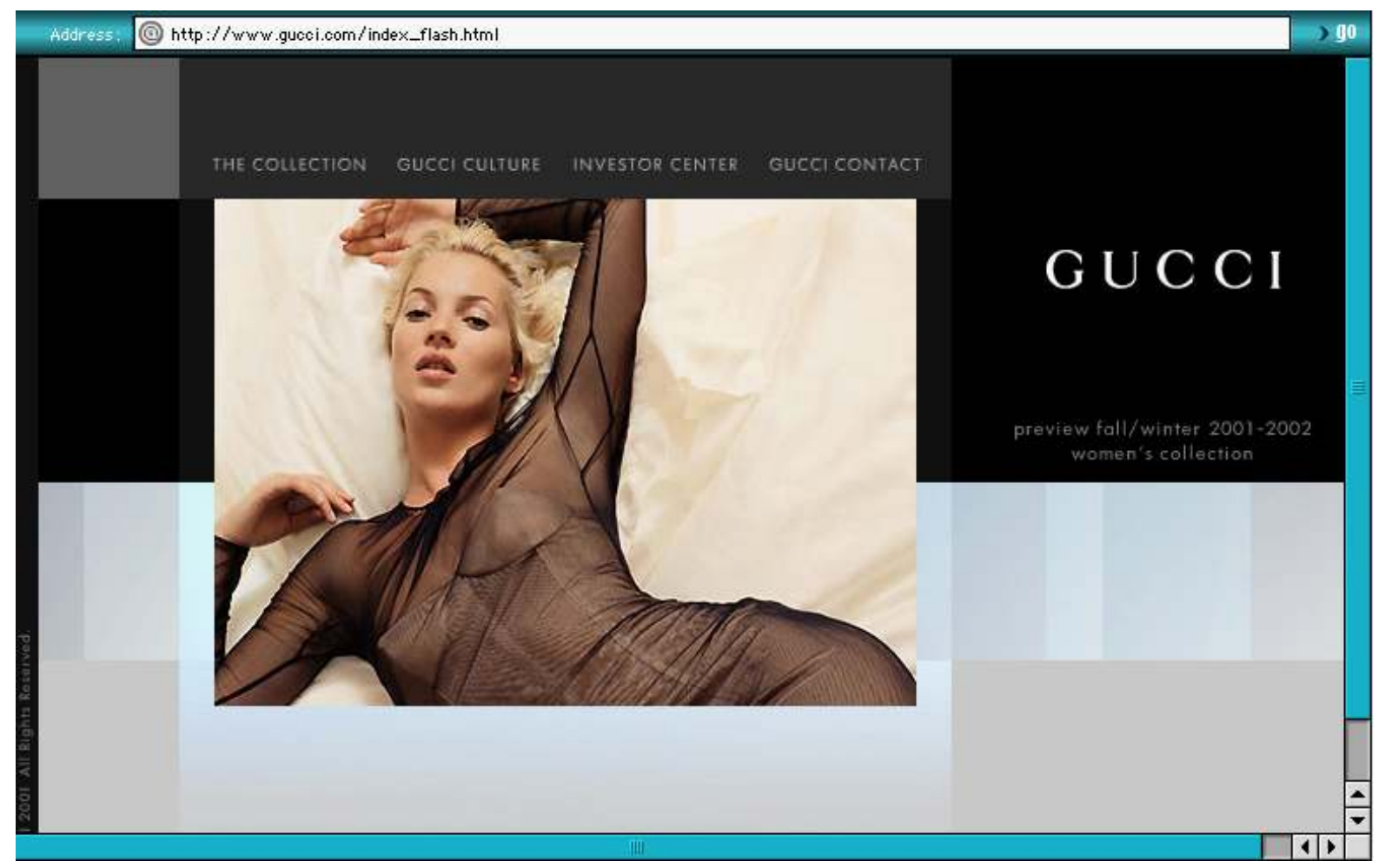

Figure 3 Idealization 


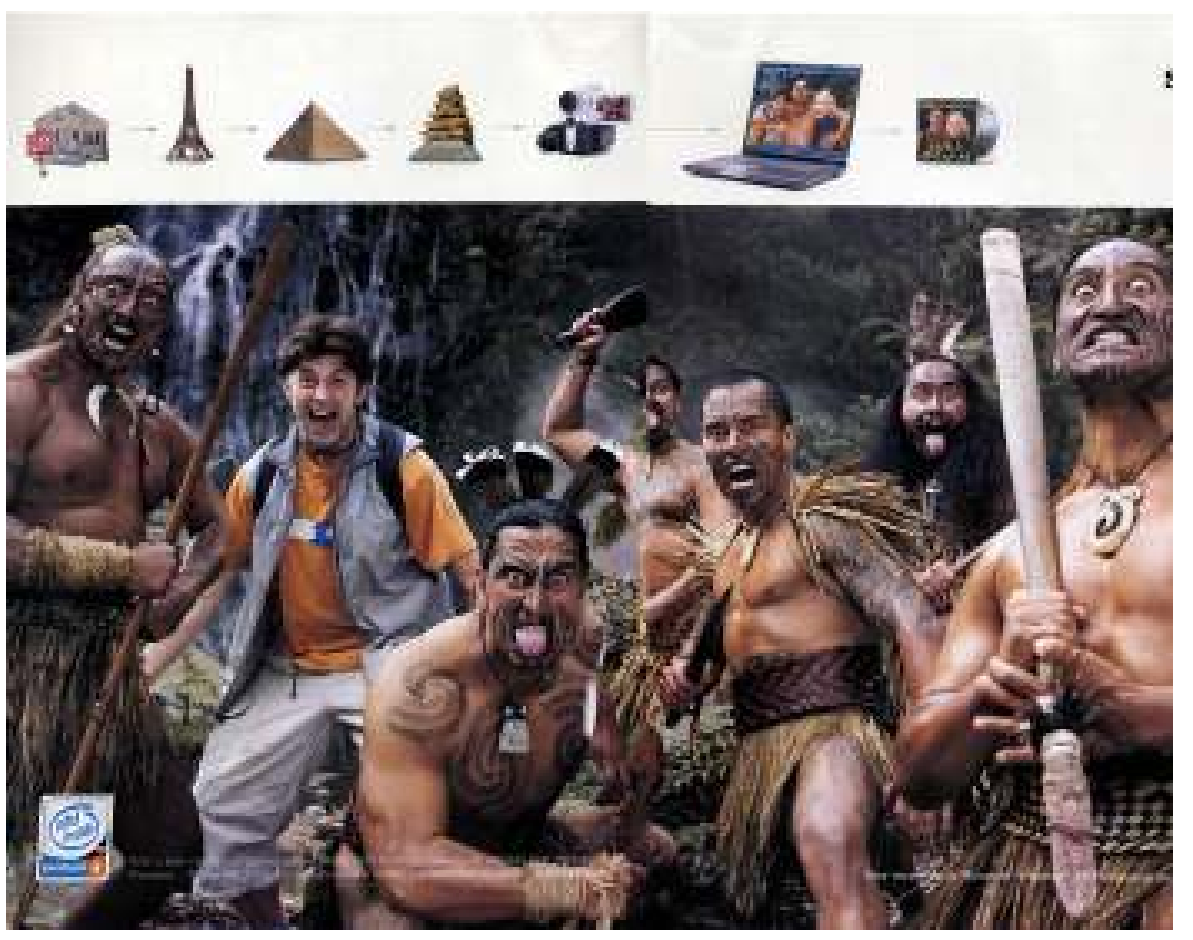

Figure 4 Exoticization 


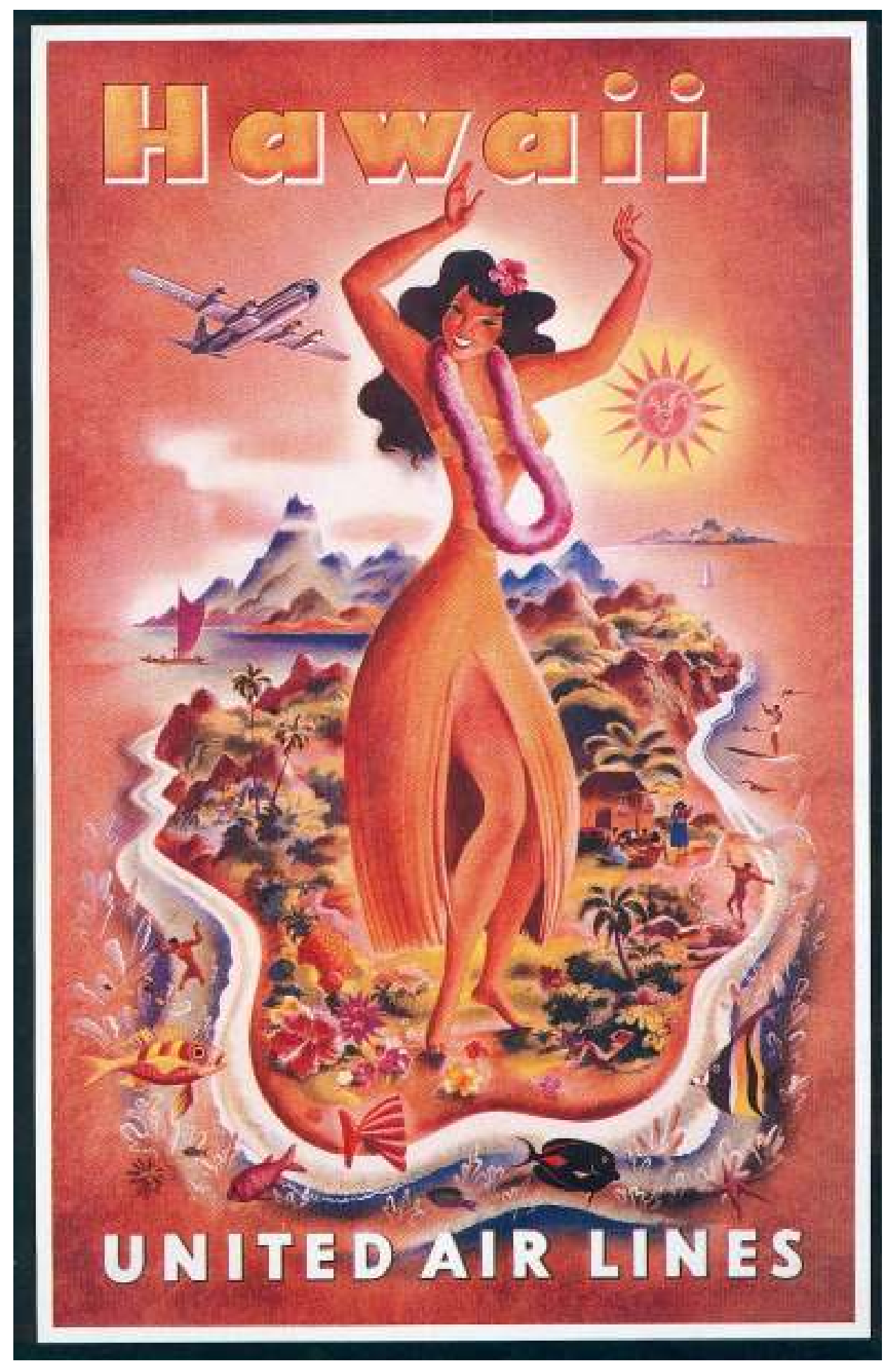

Figure 5 Exoticization 